\title{
Patterns of Exchange of Multiplying Onion (Allium cepa L. Aggregatum-Group) in Fennoscandian Home Gardens
}

\author{
Matti W. Leino ${ }^{* 1,2,6}$, Svein $\varnothing$ Solberg ${ }^{3,4}$, Hanna Maja Tunset ${ }^{5}$, \\ Jesper Fogelholm ${ }^{2}$, Else-Marie Karlsson Strese $^{6}$, and Jenny Hagenblad ${ }^{2,5}$ \\ ${ }^{1}$ The Archaeological Research Laboratory, Department of Archaeology and Classical Studies, Stockholm \\ University, SE-106 91, Stockholm, Sweden \\ ${ }^{2}$ IFM-Biology, Linköping University, SE-581 83, Linköping, Sweden \\ ${ }^{3}$ Nordic Genetic Resource Center, SE-230 53, Alnarp, Sweden \\ ${ }^{4}$ Inland Norway University of Applied Sciences, Postboks 400, 2418, Elverum, Norway \\ ${ }^{5}$ Department of Biology, Norwegian University of Science and Technology, 7491, Trondheim, Norway \\ ${ }^{6}$ Swedish Buseum of Agriculture, Nordic Museum, 27820, SE-115 93, Stockholm, Sweden \\ ${ }^{*}$ Corresponding author; e-mail: Matti.Leino@arklab.su.se
}

\begin{abstract}
Multiplying onion (Allium cepa L. Aggregatum-Group), commonly known as shallot or potato onion, has a long tradition of cultivation in Fennoscandian home gardens. During the last decades, more than 80 accessions, maintained as vegetatively propagated clones, have been gathered from home gardens in all Fennoscandian countries. A genetic analysis showed regional patterns of accessions belonging to the same genetic group. However, accessions belonging to the same genetic group could originate in any of the countries. These results suggested both short- and long-distance exchange of set onions, which was confirmed by several survey responses. Some of the most common genetic groups also resembled different modern varieties. The morphological characterization illustrated that most characters were strongly influenced by environment and set onion properties. The only reliably scorable trait was bulb skin color. Neither our morphological nor genetic results support a division between potato onions and shallots. Instead, naming seems to follow linguistic traditions. An ethnobotanical survey tells of the Fennoscandian multiplying onions as being a crop with reliable harvest, excellent storage ability, and good taste. An increased cultivation of this material on both household and commercial scale should be possible.
\end{abstract}

Key Words: Aggregating onion, shallot, potato onion, on-farm conservation, SSRs.

\section{Introduction}

Countries with highly industrialized agriculture and horticulture are often considered effectively void of landraces still being in cultivation. However, an often neglected source of biodiversity is home gardens where heirloom vegetable crops sometimes

\footnotetext{
${ }^{1}$ Received 15 November 2017; accepted 25 September 2018; published online 22 October 2018

Electronic supplementary material The online version of this article (https://doi.org/10.1007/s12231-0189426-2) contains supplementary material, which is available to authorized users.
}

have been preserved for generations (Galluzzi et al. 2010). The vegetables preserved in home gardens often have different characteristics from commercial ones, and traits such as taste, easy propagation, and storage capacity are more valued than solely high yield. In the Fennoscandian countries (Denmark, Sweden, Norway, and Finland), the typical Allium species commercially cultivated are bulb onion $(\mathrm{Al}-$ lium cepa L. Common onion-Group) and leek ( $\mathrm{Al}$ lium ampeloprasum L.), both propagated from seed of hybrid varieties. In contrast, home gardeners often use indigenous multiplying (aggregating) onion, known as shallot or potato onion (Allium cepa L. Aggregatum-Group). These onions are clonally propagated, and they rarely flower and set seed 
under Fennoscandian climatic conditions. The name potato onion probably stems from the similarity to potato propagation. Cloves of the onions are planted in the spring, and in early autumn, a cluster of, normally around ten, onions can be harvested. The onions grow fast and are hardy even in northern Scandinavia and are known for having excellent storage capacity (Nygårds and Leino 2013).

Onions (here in the sense of all edible Allium species) are mentioned already in the earliest written sources concerning Scandinavia. For example, there are reports of Vikings bringing onions on their ships during long-distance sea travel during the 10th century (Robertson 1978). Many lines of evidence suggest that multiplying onion may have been the dominating Allium species historically in the Nordic countries (Leino and Hagenblad 2014). In the early 20 th century, potato onion and shallot, usually without cultivar names, were commercially available in Denmark and Sweden (Börjeson 2015). In Finland, set onions produced in Russia were sold (Lundén 1920). It is not known whether the heirloom multiplying onions still cultivated in the 21st century are the descendants of 20th century introductions or remnants of the older cultivation tradition.

Multiplying onions have historically, as well as today, been classified as either potato onions or shallots. Bulb shape, skin color, taste, and storage capacity are often mentioned as discriminating characteristics. A clear distinction between shallot and potato onion based on such morphological characters is, however, difficult to make and sources are contradictive (Fritsch and Friesen 2002; Hanelt 1990; Rabinowitch and Kamenetsky 2002). The present Swedish standard for nomenclature of cultivated plants also differentiates between potato onion and shallot, but admits that the borders are unclear (Aldén et al. 2009). Whether shallot and potato onion form genetically differentiated groups is not known.

The Nordic gene bank (NordGen), as well as gardening NGOs and national crop biodiversity programs in the Nordic countries, has been gathering locally cultivated vegetables during the last decades (Nygairds and Leino 2013; Osara 1987). At present, more than 80 accessions of multiplying onion have been collected. Maintaining these as clones in ex situ field gene banks, however, is expensive, and identification of putative duplicate accessions as well as accessions being unique would be valuable for reducing the collection without loss of diversity. Furthermore, information on the cultural background of origin and cultivation of this crop is important for a small-scale commercialization that in turn would contribute also to in situ preservation of the crop.

Here, we present an analysis of the genetic diversity of this material, together with morphological characterizations and an ethnobotanical survey aimed to address the following questions: (1) How diverse are accessions of Fennoscandian multiplying onion?, (2) What are the geographical patterns of seed (set onion) exchange?, (3) What is the relationship to commercial clones?, and (4) Can genetic or morphological differences between potato onion and shallot be identified?

\section{Materials and Methods}

\section{Plant Material and Morphological CHARACTERIZATION}

A total of 84 locally cultivated multiplying onion accessions from Fennoscandia-Denmark, Finland, Norway, and Sweden-were studied. The accessions were obtained from NordGen, the Nordic Genetic Resource Center (accessions with prefix NGB), or from the Swedish National Program for Diversity of Cultivated Plants (accessions with prefix SWE). As a contrasting material for the genetic analysis, six local accessions from Georgia and eight modern varieties were included. These accessions were obtained from The Leibniz Institute of Plant Genetics and Crop Plant Research (IPK), Gatersleben, Germany (accessions with prefix ALL), or purchased commercially. Materials are summarized in Table 1 and the full list of accessions is given in Electronic Supplementary Material 1 (ESM). Different sets of accessions (the Fennoscandian material) have previously been test cultivated in Landvik, Norway $\left(58^{\circ} 20^{\prime} \mathrm{N}, 08^{\circ} 31^{\prime}\right.$ E) during 2001; in Aarslev, Denmark ( $55^{\circ} 18^{\prime} \mathrm{N}$,

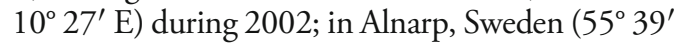

TABLE 1. GROUPS OF ACCESSIONS USED IN THE STUDY AND GENETIC DIVERSITY WITHIN GROUPS.

\begin{tabular}{lcc}
\hline \hline Group & $\begin{array}{l}\text { No. of } \\
\text { accessions }\end{array}$ & $\begin{array}{l}\text { Genetic diversity within } \\
\text { group (Nei's h) }\end{array}$ \\
\hline Denmark, landraces & 24 & 0.48 \\
Finland, landraces & 14 & 0.58 \\
Georgia, landraces & 6 & 0.23 \\
Norway, landraces & 17 & 0.58 \\
Sweden, landraces & 29 & 0.52 \\
Modern varieties & 8 & 0.66 \\
Total & 98 & \\
\hline
\end{tabular}


$\mathrm{N}, 13^{\circ} 04^{\prime}$ E) during 2009-2011; in Röttle, Sweden $\left(57^{\circ} 59^{\prime} \mathrm{N}, 14^{\circ} 25^{\prime} \mathrm{E}\right)$ during 2011; or in Julita, Sweden $\left(59^{\circ} 08^{\prime} \mathrm{N}, 16^{\circ} 02^{\prime} \mathrm{E}\right)$ during 2013-2014. They were scored for relevant morphological characters according to IPGRI descriptors for Allium spp. (IPGRI, ECP/GR, AVRDC 2001). Data from these test cultivations are assembled (ESM 1).

\section{Genetic AnALysis}

Green shoots or the innermost layers of onion bulbs ( $<100 \mathrm{mg}$ fresh weight) were used for DNA extraction. The extractions were performed using either the E.Z.N.A Plant DNA kit from Omega Biotek (Omega Biotek, GA, USA) or the DNeasy plant mini kit from Qiagen (Qiagen $A B$, Germany) in accordance with the manufacturers' instructions. Genotyping was performed using 12 microsatellite markers originally designed for bulb onion (Allium cepa Common onionGroup) (Fischer and Bachmann 2000). Table 2 presents the studied markers, primer sequences, and temperatures. The PCRs were performed in a total reaction volume of $20 \mu \mathrm{l}$ containing $0.2 \mu \mathrm{M}$ forward primer fluorescently labeled with either FAM or HEX, $0.2 \mu \mathrm{M}$ reverse primer, $0.25 \mu \mathrm{M}$ each of dNTPs, 60-100 ng template DNA, and 0.5 U Dream Taq DNA polymerase and supplied buffer (Fermentas, Hanover, MD). The PCR cycling parameters were denaturation for $3 \mathrm{~min}$ at $94^{\circ} \mathrm{C}$ followed by 35 cycles of $15 \mathrm{~s}$ of denaturation at $94{ }^{\circ} \mathrm{C}, 30 \mathrm{~s}$ annealing at $52-62{ }^{\circ} \mathrm{C}, 30 \mathrm{~s}$ of extension at $72{ }^{\circ} \mathrm{C}$, and final elongation step of $72{ }^{\circ} \mathrm{C}$ for $10 \mathrm{~min}$. PCR fragment lengths were analyzed by capillary gel electrophoresis and confocal laser scanning using an ABI 31030x1 genetic analyzer. Alleles were identified using the software Geneious version 6.1.8 (Kearse et al. 2012).

Genetic diversity within groups (Nei's $h$, Nei 1973) and genetic differentiation between groups (Wrights $F_{\mathrm{ST}}$, Wright 1951) were calculated using purpose-written Perl scripts. The spatial genetic structure of the accessions was studied with principal component analysis (PCA) performed using the $\mathrm{R}$ statistical software ( $\mathrm{R}$ Development Core Team 2013, version 3.02). The same software was used for analysis of population structure with discriminant analysis of principal components (DAPC) using the adegenet package (Jombart et al. 2010). The DAPC analysis was repeated ten times, after which individual runs were merged using the software CLUMPP (v 1.1.2) (Jakobsson and Rosenberg 2007). The obtained clusters were mapped in ArcGIS 10.0 (ESRI 2011).

\section{Ethnobotanical SuRVEY}

An ethnobotanical survey was sent to the donors of the accessions included in the investigation. Since many of the accessions were gathered more than 20 years ago, many donors were no longer alive or their whereabouts could not be traced. This was in particular the case for the Finnish accessions. In total, current addresses of

TABLE 2. MARKERS, PRIMER SEQUENCES, AND CORRESPONDING ANNEALING TEMPERATURES.

\begin{tabular}{lllc}
\hline \hline Marker & $\begin{array}{l}\text { Primer sequence } \\
\text { Forward }\end{array}$ & $\begin{array}{l}\text { Primer sequence } \\
\text { Reverse }\end{array}$ & $\begin{array}{l}\text { Annealing temperature } \\
\left({ }^{\circ} \mathrm{C}\right)\end{array}$ \\
\hline AMS02 & GCA TTA ACT ATC TAA AAC ATT G & CCA TCA ACT CAT AAC AGG T & 53 \\
AMS06 & GGT GCA TAG GGT CTC ATC TG & ATT GAT TGT TTG TTT GGA TGT & 56 \\
& & G & 55 \\
AMS08 & GCC ACG ATG TTG AGA TTT CG & CCC GAA TAT CCC ACC AGT TC & 58 \\
AMS12 & AAT GTT GCT TTC TTT AGA TGT TG TGC AAA ATT ACA AGC AAA CTG & TG \\
AMS14 & CCC CTG AGT AAA TTC AAA ATC C & TCC TTA GTA TAA TTT CGG GGT & 62 \\
& & AAC & 57 \\
AMS16 & CTG CAT TAA AAC AAC CAA ACT TG & GAG CTC CAC TTC TTC CAA ACT & 59 \\
& & AG & 59 \\
AMS20 & TTG AGC AGC AGA ACC AGA C & ATT CGG ACG CAA CAC ATC & 56 \\
AMS21 & GGT TGT TTC CAC TAC ACT TGA G & CGT CCT TGG TAT TCT TGT GC \\
AMS22 & CAC CGT TTC CAT AAT CAA GG & ATT TTT TGG GCA TTG TTG G & 58 \\
AMS23 & GCT GTT CAC TGG TCT ATC TGG & ATT CGG TGC TGA TTT TCG & 57 \\
AMS25 & GAG GGC AGT GTT AGC ATT CC & GCA ACC TTT CCC CGA GAG & 61 \\
AMS30 & CAC TAA TGG GGT AAA TAA TGT & TTG CCT TGA AAT CCA GAC & 57 \\
\multicolumn{2}{c}{ TCT AC } & & \\
\hline
\end{tabular}


50 donors could be found and surveys were sent out to these donors. The survey included questions of donor taxon name (shallot or potato onion) as well as local name of the accession, cultivation practices, phenology, history, and use (ESM 2).

\section{Results}

\section{MORPHOLOGY}

Data from cultivation experiments of potato onion at NordGen and the different Nordic programs for biodiversity in cultivated plants were assembled and compared. Many accessions were included in repeated test cultivations, and thus the reliability of the scored characters could be compared. Although there was obvious morphological variation among the material (Fig. 1), characters seemed to be strongly influenced by environment and set onion properties besides genotype. This was especially the case for quantitative traits, such as scores of the size and number of onions produced from each set onion, with large variation among experiments and a strong influence from the size of the set onion. The large variation observed, combined with effects of differences of years and growing locations, limits the possibility to draw conclusions of any quantitative data, and these are therefore not presented. Bulb shape is more of a qualitative character, but was partly differently scored among experiments, where the same accession could produce flattened, round, rhomboid, and high top bulbs. A predominant shape could, however, be assigned to most accessions (ESM 1).

The only character with consistent scoring among experiments was the bulb skin color. This

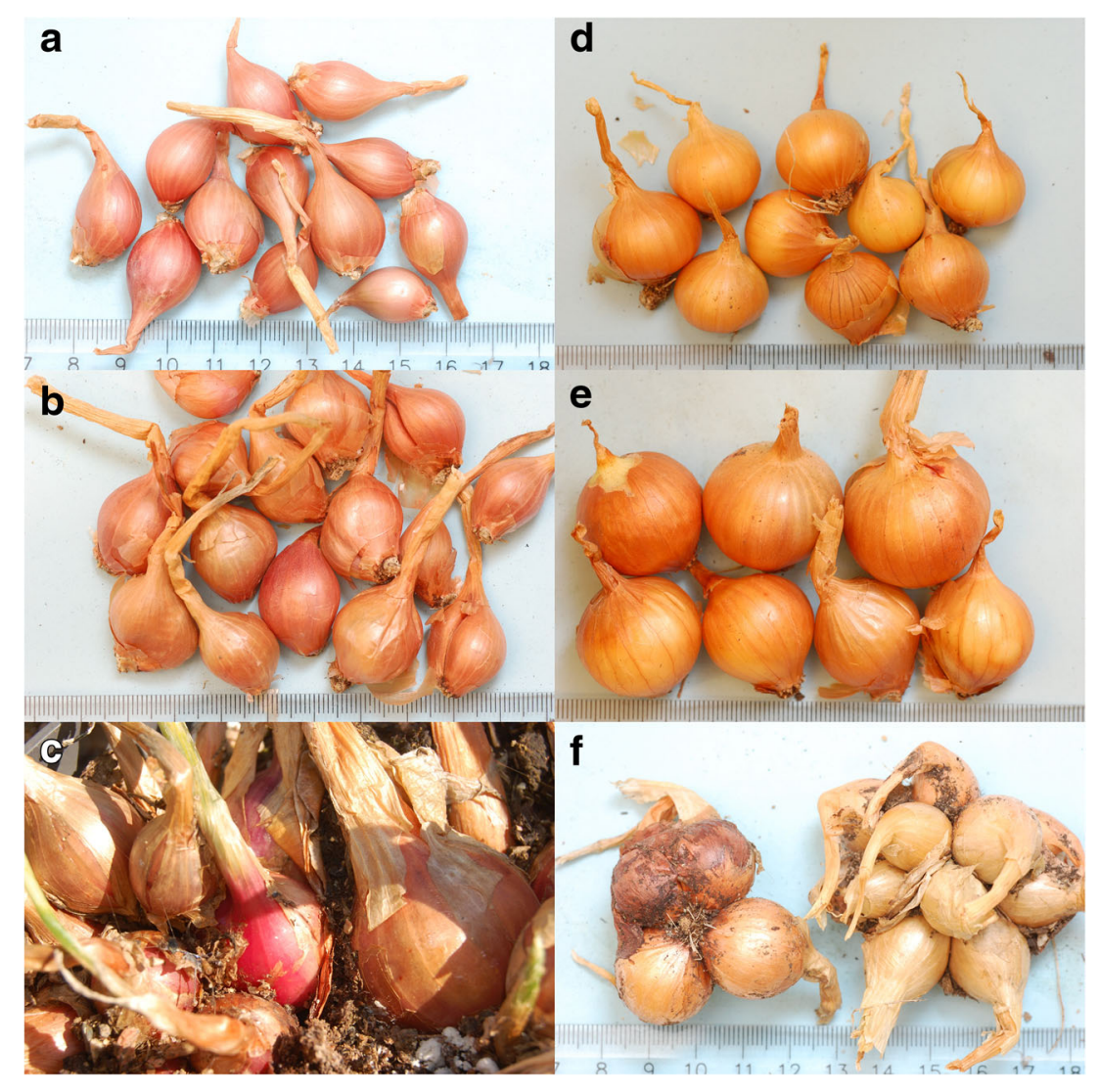

Fig. 1. Examples of morphological variation of Nordic multiplying onions. Note accessions with purple skin color (left) and yellow to brown skin color (right). a NGB17770 from Norway. b SWE104 from Sweden. c NGB8315 from Finland. d NGB16537 from Denmark. e NGB17975 from Norway. f NGB17973 from Finland. 
could be classified as either predominantly yellowbrown or red (ESM 1). In all cases where the bulb skin color was red, the flesh color was violet-white, whereas accessions with yellow-brown skin had green-white flesh. Of the 86 accessions scored, nine had red skin and the remaining accessions had yellow-brown skin. The red-skinned accessions were found in all Fennoscandian countries except Denmark.

\section{Genetic Analysis}

We performed molecular genotyping using 12 microsatellite markers. The markers, originally developed for bulb onion, worked well with multiplying onions and yielded relatively consistent results with one or two deviating alleles when the same accessions were subjected to repeated genotyping.

Genetic diversity was calculated for accessions from each country as well as the group of modern varieties (Table 1). The highest diversity was found among the modern varieties, whereas accessions from Georgia were the most homogenous. For the four Fennoscandian countries, only small differences in within-country diversity were found. Genetic differentiation was calculated between groups of accessions from each country (Table 3). Pairwise comparisons between Denmark, Norway, and Sweden resulted in low and non-significant $F_{\mathrm{ST}}$ values, indicating low differentiation between accessions in these countries. In contrast, Finland, compared to the Scandinavian countries, showed higher and significant $F_{\mathrm{ST}}$ values. The accessions from Georgia were highly differentiated from all other groups. The modern variety group showed high $F_{\mathrm{ST}}$ values in comparison to all other groups except the accessions from Finland, suggesting a closer genetic relationship between the Finnish accessions and the modern varieties included in the study.

To visualize differentiation of accessions within and between countries and investigate links to morphology and nomenclature, we performed principal component analysis (PCA). This analysis again showed the clear differentiation of the homogenous group of accessions from Georgia from the Fennoscandian material. The modern varieties were well separated from each other and in many cases located away from the Fennoscandian onions, however with notable exceptions (Fig. 2a). Looking only at accessions from the Fennoscandian countries, a large group of genetically similar accessions was identified (Fig. 2b, group I). This group included several accessions from all four countries, in particular Denmark. Two minor groups with genetically similar accessions were also found (Fig. 2b, groups II and III) as well as several accessions that were more genetically unique. We further investigated whether the morphologically stable skin color trait was mirrored in the genetic analyses (Fig. 2c). Although the major cluster only contained yellowbrown skinned accessions, no clear clustering of red and yellow-brown accessions, respectively, was found. Similarly, genetic clustering was not associated with nomenclature, and the same cluster could contain both accessions called "shallot" and those called "potato onion." On the contrary, the different clusters contained accessions with both names (Fig. 2d).

To geographically visualize distribution of genetic variability, we performed discriminant analysis of principal components (DAPC). In the model, we used ten different genetic groups as BIC values formed a plateau around this number (data not shown). The proportion of assignment to each group for each accession was plotted on a map at the location of the origin of the accession (Fig. 3). The most common group (light green) was frequently found in Denmark, especially Jutland, but also in Sweden and along the Norwegian coast. In addition, three of the Finnish accessions primarily belonged to this group. Another group (purple) seems particularly common in eastern Denmark

TABLE 3. $F_{\text {ST }}$ VALUES FOR PAIRWISE COMPARISONS BETWEEN COUNTRIES OF ORIGIN. AVERAGE $F_{\text {ST }}$ VALUES ACROSS LOCI.

\begin{tabular}{llllll}
\hline \hline & Georgia & Finland & Sweden & Norway & Denmark \\
\hline Finland & $0.247^{* * *}$ & & & & \\
Sweden & $0.246^{* * *}$ & $0.115^{* * *}$ & & & \\
Norway & $0.274^{* * *}$ & $0.110^{* * *}$ & 0.019 & 0.023 & $0.109^{* * *}$ \\
Denmark & $0.292^{* * *}$ & $0.135^{* * *}$ & 0.008 & $0.084^{* * *}$ & $0.082^{* * *}$ \\
Modern varieties & $0.267^{* * *}$ & 0.032 & & & \\
\hline
\end{tabular}

*** Significant at $P=0.001$ 

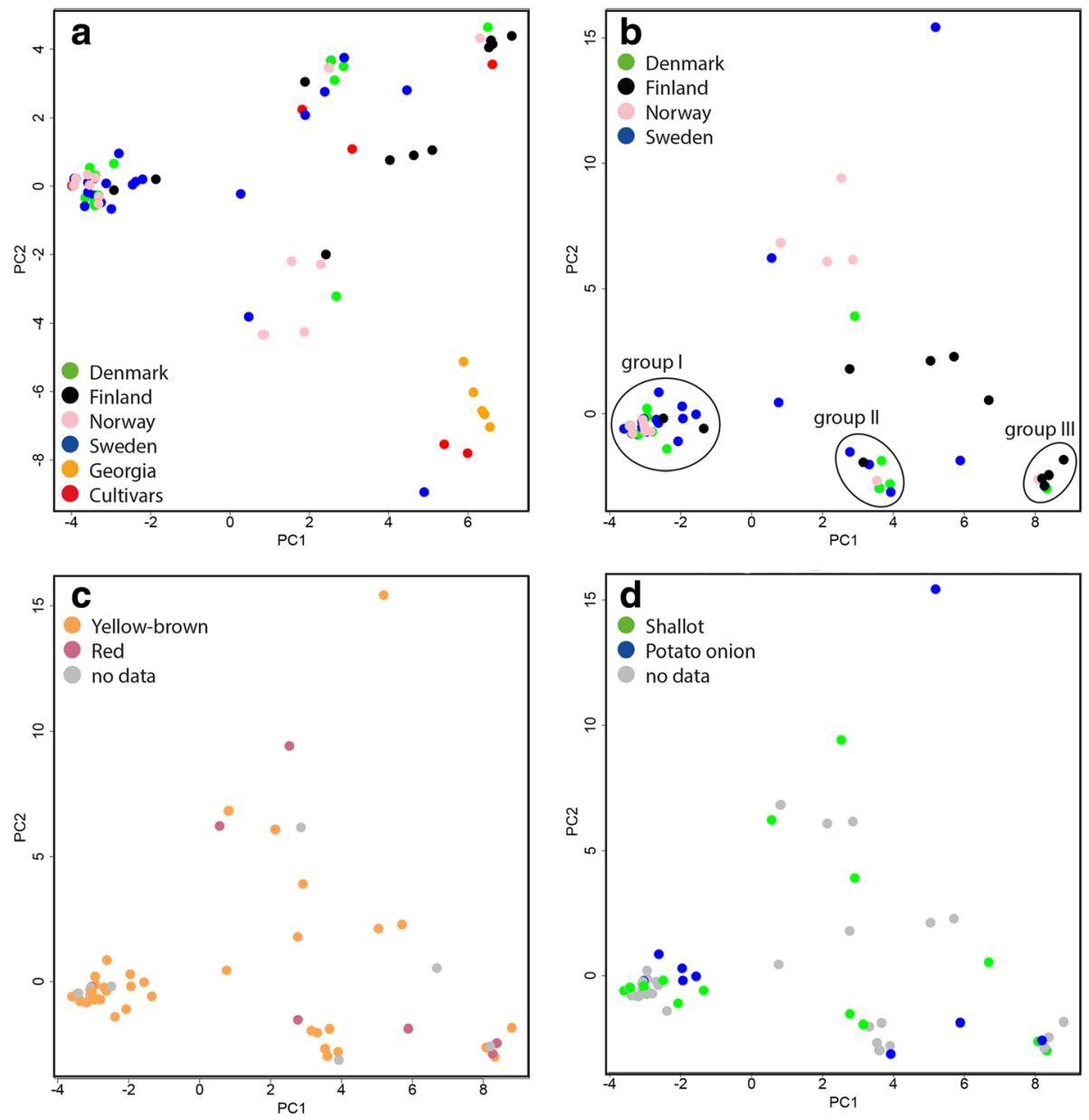

Fig. 2. Principal component analyses (PCA) of SSR genotyping of multiplying onions. a All accessions, marked by country of origin. $\mathbf{b}$ All Nordic accessions, marked by country of origin. c All Nordic accessions, marked by bulb skin color. $\mathbf{d}$ All Nordic accessions, marked by name. In a, PC1 explains $20.14 \%$ of the variation and PC2 $10.65 \%$; in b-d, PC1 explains $23.67 \%$ of the variation and PC2 $12.83 \%$.

and southernmost Sweden, but single accessions belonging to this group were also found in Norway, northern Sweden, and Finland. The most common Finnish group (brown) was also represented, with one accession in Denmark and one in Norway. The yellow group was only found in a few accessions from southernmost Sweden. Accessions including the dark blue and purple group were found in Norway and Finland, but not in Denmark or southern Sweden. Other minor groups had no obvious geographical distribution. In summary, although some geographical distribution patterns can be seen, many genetic groups are spread over all of Fennoscandia.

Since multiplying onions are mainly vegetatively propagated, a high degree of clonality among accessions was expected. We identified eight genotypes that were shared by two or more accessions. The most common genotype was found in 13 accessions, mainly from Denmark. The two second most common genotypes were each found in five accessions. The first of these two genotypes was represented by accessions from Denmark, Norway, and Sweden, and the second genotype by accessions from Denmark and Sweden and the modern variety 'Success.' All the three most common genotypes (comprising 23 accessions) were closely related to each other, differing only in single locus. They belong completely or mainly to the light green genetic group in Fig. 3 and are included in group $\mathrm{I}$ in Fig. 2b. The remaining shared genotypes were 


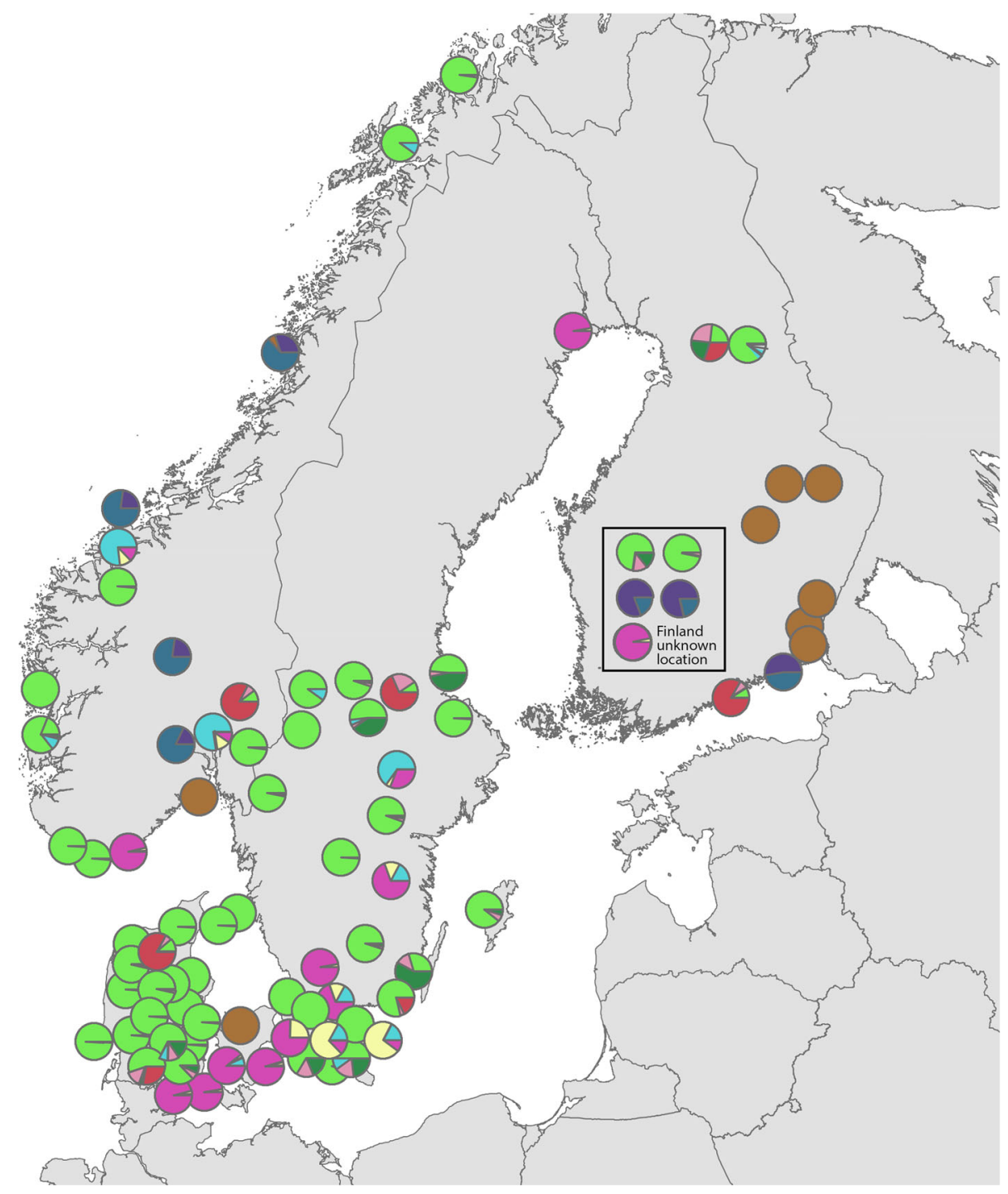

Fig. 3. Geographical visualization of DAPC clustering of Nordic multiplying onions. Pie charts show the proportion of designation to each of $N$ clusters. Finnish accessions with unknown location of origin are shown in a separate block.

represented by two or three accessions. Noteworthy are the accessions NGB8315 and NGB17967 from Finland that have identical genotypes to the modern variety 'Santé.'

\section{Survey Results}

A total number of 24 survey responses were received (48\%). The majority of responses were from Denmark and Sweden. The replies are summarized in Table 4, but not all respondents replied to all questions. All respondents from Denmark and Norway responded they knew only "shallot" and therefore could not distinguish between the types "potato onion" and "shallot" (Table 4). Two of the Swedish respondents replied similarly (respondents SWE85 and SWE86) and another two that shallots and potato onion were the same (respondents SWE96 and SWE84). One respondent claimed that potato onion stores better 
TABLE 4. SUMMARIZED INFORMATION FROM THE ETHNOBOTANICAL SURVEY.

\begin{tabular}{lcl}
\hline \hline Trait & Number of responses & Comments \\
\hline Donor taxon name & & \\
Shallots $(S)$ & 16 & Denmark and Norway: all S, Sweden: $6 / 14=\mathrm{S}$ \\
Potato onion (P) & 5 & Denmark and Norway: no P, Sweden: $5 / 14=\mathrm{P}$ \\
Other names & 3 & \\
No answer & 2 & \\
Size of set onion & 11 & \\
$\quad$ Small & 1 & Medium-sized mentioned by five of the nine respondents \\
Large & 9 & \\
Other criteria & 5 & \\
No answer & & \\
Flowering & 12 & \\
No & 8 & \\
Yes, sometimes & 6 & \\
No answer & 7 & \\
Keeping ability & 6 & \\
Until spring & 4 & \\
Approx. 1 year & 7 & \\
More than 1 year & & \\
No answer & & \\
\hline
\end{tabular}

than shallots (respondent SWE87), and another claimed that potato onion was more circular in shape and tasted better than shallots (respondent SWE89).

Regarding cultivation and phenology, most respondents used small- or medium-sized bulbs for cultivation (Table 4). Cultivation was done by planting in rows (at various distances) in spring. Harvesting was done in late summer when leaves were dry. No clear patterns were detected between donor taxon name and the size of bulbs used for cultivation or other cultivation practices. More than half of the respondents had never observed flowering plants among the onions (Table 4). Of the respondents that confirmed flowering, most claimed that this was occurring only at low frequency. One of the respondents (SWE82) reported that $1-2 \%$ of the onions planted flowered. Another respondent claimed that flowering occurred after early planting (respondent SWE89). No clear relationship was detected between donor taxon name and flowering. None of the respondents had ever obtained or used true seed for propagation.

The keeping ability varied from over the winter until more than 2 years (Table 4). Dry and cool storage conditions were mentioned as important by most respondents. A proper outdoor curing period prior to storing was mentioned by a few respondents as important to avoid decay (SWE82, SWE106). Storing on nets or in thin layers in boxes was reported (respondents NGB16552 and 16549). Others mention storing in the boiler room or cellar (SWE58, SWE89, SWE96).

For many of the respondents, the histories of the plants were highlighted, in some cases with a long story dating back at least 50 years. Often, the onions were given from one generation to the next within a family. When details were present, a mother to daughter line could often be detected (in Scandinavian "mormor"). Only in one case was a male mentioned (respondent NGB16555). The onions were used in a lot of different dishes and no clear pattern or country differences were detected.

\section{Discussion}

Although no common cultivation experiment with all accessions included has been performed, the comparison of data clearly showed the difficulty in performing characterization of accessions based on morphological characters. The only character that showed a consistent scoring among experiments was red skin color, co-occurring with violet flesh color. Accessions with these traits were, however, not apparently genetically related (Fig. 2c). Other morphological characters as well as agronomic performance seem to be strongly influenced by environmental factors, properties of the set onions, and possibly genotype-environment interactions. We chose not to report quantitative data as these would have 
required growth trials of all accessions in parallel to be comparable. Repeated experiments in multiple years and locations will be required to evaluate the effects of genotype, environment, and interactions.

A number of potential clones, i.e., accessions with identical genotypes, were identified. It must be noted that the number of genetic markers is small and that more markers could putatively reveal genetic differences between accessions here considered as potential clones. Conversely, there is also a small risk of genotyping errors due to stuttering in the microsatellite analysis that, for example, make differentiation between homozygous and heterozygous loci difficult (Shinde et al. 2003). Likewise, although the proportion of missing data was very low (4.7\% across genotyped loci), the sporadic missing data, so-called allelic dropout, could mean accessions have been identified as identical or more similar than they in fact are. Taken together, this means the number of identical clones could be either higher or lower than the numbers presented above. In spite of these concerns, we can with confidence identify a high degree of clonality among the Fennoscandian multiplying onions. This is expected as this plant material has historically and at present only been propagated vegetatively (Nygårds and Leino 2013). The survey results confirmed that flowering is very rare and that seed propagation (i.e., sexual reproduction) is never used in Nordic cultivation of multiplying onions.

The high degree of clonality differs from results obtained in other vegetatively propagated crops in Fennoscandia. In hops (Humulus lupulus L.), no identical clones were found when comparing accessions from different Swedish locations (Strese et al. 2014). Likewise, in horseradish (Armoracia rusticana G. Gaertn., B. Mey. \& Scherb.) collected from Nordic gardens, low clonality was found (Wedelsbäck Bladh et al. 2014). For these crops, repeated introductions over a long period of time and possible sexual reproduction were suggested. The contrasting results obtained for Fennoscandian multiplying onions would suggest that onions have instead been introduced at only a few occasions and then multiplied and spread within Fennoscandia.

Three genetic groups, each including several accessions, could each be linked to modern varieties. The first and largest group of accessions being genetically identical or nearly identical (group I in Fig. $2 \mathrm{~b}$, light green in Fig. 3) is closely related to the modern variety 'Success.' This type was dominating in Denmark, but was also common in Norway and occurred also in Finland and Sweden. A second group of genetically similar accessions includes the modern variety 'Santé' (group III in Fig. 2b, brown in Fig. 3). These accessions were common in Finland, but were also present in Denmark and Norway. A third group (group II in Fig. 2a, purple in Fig. 3) contained several accessions from southeast Denmark and occasional accessions from Sweden, Finland, and Norway as well as the modern variety 'Red Sun.' Some of the Finnish accessions with unknown origin (boxed in Fig. 3) might also be of modern variety or breeding material origin according to passport data. Whether these Fennoscandian landrace accessions, being genetically identical to commercial cultivars, actually originate from commercially marketed set onions is not clear. Another possibility is that these accessions are genuine landraces and that the same clones have been gathered and commercialized by seed companies. Although shallot and potato onion have been marketed in Fennoscandia since the 1850s, cultivar names are rarely indicated (Börjeson 2015). Whatever the history of these accessions and their commercial counterparts, the clones or types have apparently been highly appreciated and set onions have been shared and spread widely.

Besides the major groups, the genetic analysis identified a handful of genetically unique clones represented by one or only a few accessions. The clustering of genetically similar or identical accessions in narrow geographical areas is likely explained by sharing of set onions from gardener to gardener within families or in local networks. The exchange of plant material is also confirmed in many of the survey answers where the history of specific accessions can be traced back to several different growers many decades, sometimes up to 100 years ago. None of the respondents reported an origin in commercial purchase of set onions. This does not rule out that some of the multiplying onions have an origin from commercial retailers, but clearly the onions have been maintained and spread by household gardeners for several decades. In the cases where identical clones occur geographically widespread, an involvement from retailers of plant material could be assumed to be more likely. However, several survey respondents said that set onions had been brought along when the respondents or their ancestors had moved within or between the Fennoscandian countries.

Looking at a wider geographical pattern, accessions from the Scandinavian countries-Sweden, Norway, and Denmark - share substantial genetic identity, although some genetic groups are country-specific. In Finland, diversity is higher and the country-wise $F_{\mathrm{ST}}$ 
comparisons separate the Finland from the other counties. One reason, which also explains a lower $F_{\mathrm{ST}}$ in comparison to modern varieties, is a high number of accessions identical or similar to the variety Santé. The results may suggest a different route of introduction of multiplying onions to Finland. Historical sources from the early 20th century mention that set onions were regularly imported to Finland from southern Russia where the onions were propagated from true seed (Lundén 1920). The accessions from Georgia were, however, with the exception of a Swedish accession, not very closely related genetically to the Nordic material. Analyses of more onions from Russia and possibly also the Baltic states could answer whether Finnish multiplying onions have closer genetic resemblance to eastern European onions, which would suggest an Eastern European introduction route.

A long-standing question has been the differences and similarities between shallot and potato onion. Among our material, we could not observe any morphological features that characterized accessions denoted either as shallots or potato onions by the home growers. For example, the morphological character giving the most consistent scoring, color, was clearly not associated with naming. Other morphological characters were very unstable, but could possibly be identified in test cultivations of all accessions at the same location and with set onions of homogenous size. Accessions named shallots and potato onions did not group genetically in any way either (Fig. 2d). In fact, genetically identical accessions occur where one accession is denoted potato onion and the other shallot. The only clear pattern among Fennoscandian multiplying onions is linguistic. In Norwegian and Danish, all multiplying onions are called shallots. In Swedish and Finnish, the names shallot and potato onion are alternatively used. The lack of morphological or genetic distinguishing features contradicts historical literature where shallot and potato onion are clearly separated (Lyttkens 1904 and references therein). One explanation might be that historical sources referring to shallot might actually refer to gray shallot, nowadays identifying as another species, Allium oschaninii O. Fedtsch (Maaß 1996). There is, however, no evidence of any actual cultivation of gray shallot in the Nordic countries.

Multiplying onion has long been neglected by commercial growers in the Nordic countries, but instead maintained in household gardens. This is now beginning to change with an emerging interest among chefs for locally produced food with cultural traditions. In addition, multiplying onion is highly appreciated for excellent taste. Thus, an increased commercialization of multiplying onion could be expected. Based on our data, accessions with contrasting genotypes could be chosen for cultivation experiments and identification of suitable accessions for different purposes.

\section{Acknowledgments}

Dr. Rie Henriksen is acknowledged for assistance with translating Danish surveys, and Dr. Terhi Suojala-Ahlfors for assistance with passport data for Finnish accessions.

\section{Funding Information}

This work was supported by the Swedish Board of Agriculture within the frame of the National Program for Diversity of Cultivated Plants (POM).

Open Access This article is distributed under the terms of the Creative Commons Attribution 4.0 International License ( h t t p:// creativecommons.org/licenses/by/4.0/), which permits unrestricted use, distribution, and reproduction in any medium, provided you give appropriate credit to the original author(s) and the source, provide a link to the Creative Commons license, and indicate if changes were made.

\section{Literature Cited}

Aldén, B., S. Ryman, and M. Hjertson. M. 2009. Våra kulturväxters namn: Ursprung och användning. Stockholm: Formas.

Börjeson, A. 2015. Sorter av köksväxter. Svenska priskuranter från 1800-talet till 1930. NordGen Publication Series 2015:01.

ESRI. 2011. ArcGIS Desktop: Release 10. Redlands, California: Environmental Systems Research Institute.

Fischer, D. and K. Bachmann. 2000. Onion microsatellites for germplasm analysis and their use in assessing intra- and interspecific relatedness within the subgenus Rhizirideum. Theoretical and Applied Genetics 101(1-2): 153-164.

Fritsch, R. M. and N. Friesen. 2002. Evolution, domestication and taxonomy. Allium crop science: Recent advances, eds. H. D. Rabinowitch and L. Currah, 5-30. Wallingford, Great Britain: $\mathrm{CAB}$ International.

Galluzzi, G., P. Eyzaguirre, and V. Negri. 2010. Home gardens: Neglected hotspots of agro- 
biodiversity and cultural diversity. Biodiversity and Conservation 19(13):3635-3654.

Hanelt, P. 1990. Taxonomy, evolution and history of Alliums. In Onions and other vegetables, eds. H. D. Rabinowitch and J. L. Brewster, 1-26. Boca Raton, Florida: CRC Press, Inc.

IPGRI, ECP/GR, AVRDC. 2001. Descriptors for Allium (Allium spp.). International Plant Genetic Resources Institute, Rome, Italy; European Cooperative Programme for Crop Genetic Resources Networks (ECP/GR); Asian Vegetable Research and Development Center, Taiwan.

Jakobsson, M. and N. A. Rosenberg. 2007. CLUMPP: A cluster matching and permutation program for dealing with label switching and multimodality in analysis of population structure. Bioinformatics 23(14):1801-1806.

Jombart, T., S. Devillard, and F. Balloux. 2010. Discriminant analysis of principal components: A new method for the analysis of genetically structured populations. BMC Genetics 11:94. https://doi.org/10.1186/1471-2156-11-94.

Kearse, M., R. Moir, A. Wilson, S. Stones-Havas, M. Cheung, S. Sturrock, S. Buxton, A. Cooper, S. Markowitz, C. Duran, T. Thierer, B. Ashton, P. Mentjies, and A. Drummond. 2012. Geneious Basic: An integrated and extendable desktop software platform for the organization and analysis of sequence data. Bioinformatics 28(12):1647-1649.

Leino, M. W. and J. Hagenblad. 2014. Potato onion-The missing link to onion cultivation in the past? Bulletin för trädgårdshistorisk forskning 27:17-19.

Lundén, O. 1920. Köksväxtodling: Handbok i köksväxternas odling för trädgårdsodlare och trädgårdsundervisningen i Finland. Stockholm, Sweden: Norstedt.

Lyttkens, A. 1904. Svenska växtnamn. Lund: Ekstrand.
Maaß, H. I. 1996. About the origin of the French grey shallot. Genetic Resources and Crop Evolution 43(3):291-292.

Nei, M. 1973. Analysis of gene diversity in subdivided populations. Proceedings of the National Academy of Science USA 70: 3321-3323.

Nygårds, L. and M. W. Leino. 2013. Klint Karins kålrot och Mor Kristins böna. Om Fröuppropets kulturarv. Alnarp, Sweden: POM.

Osara, K. 1987. Kotimaisen ryvässipulin elvytys. Puutarha 10:710-712.

R Development Core Team. 2013. R: A language and environment for statistical computing. Vienna, Austria: R Foundation for Statistical Computing.

Rabinowitch, H. D. and R. Kamenetsky. 2002. Shallot (Allium cepa Aggregatum-Group). In Allium crop science: Recent advances, eds. H. D. Rabinowitch and L. Currah, 409-430. Wallingford, Great Britain: CAB International.

Robertson, D. 1978. Attitudes toward nutrition and health in the Ancient North. Southern Medical Journal 71(12):1562-1566.

Shinde, D., Y. L. Lai, F. Z. Sun, and N. Arnheim. 2003. Taq DNA polymerase slippage mutation rates measured by PCR and quasi-likelihood analysis: $(\mathrm{CA} / \mathrm{GT})(\mathrm{n})$ and $(\mathrm{A} / \mathrm{T})(\mathrm{n})$ microsatellites. Nucleic Acid Research 31(3):974-980.

Strese, E. M. K., M. Lundström, J. Hagenblad, and M. W. Leino. 2014. Genetic diversity in remnant Swedish hop (Humulus lupulus L.) yards from the 15th to 18th century. Economic Botany 68(3):231-245.

Wedelsbäck Bladh, K., E. Liljeroth, G. Poulsen, F. Yndgaard, and A. K. Brantestam. 2014. Genetic diversity in Nordic horseradish, Armoracia rusticana, as revealed by AFLP markers. Genetic Resources and Crop Evolution 61(2):383-394.

Wright, S. 1951. The genetical structure of populations. Annals of Eugenics 15:323-354. 